NASA-CR-205091

\title{
Tracer lamination in the stratosphere: A global climatology
}

\author{
Christof Appenzeller ${ }^{1}$ and James R. Holton \\ Department of Atmospheric Sciences, University of Washington, Seattle
}

\begin{abstract}
Vertical soundings of stratospheric ozone often exhibit laminated tracer structures characterized by strong vertical tracer gradients. The change in time of these gradients is used to define a tracer lamination rate. It is shown that this quantity can be calculated by the cross product of the horizontal temperature and horizontal tracer gradients. A climatology based on UARS satellite-borne ozone data and on ozone-like pseudotracer data is presented. Three stratospheric regions with high lamination rates were found: the part of the stratospheric overworld which is influenced by the polar vortex, the part of the lowermost stratosphere which is influenced by the tropopause and a third region in the subtropical lower stratosphere mainly characterized with strong vertical shear. High lamination rates in the stratospheric overworld were absent during summer, whereas in the lowermost stratosphere high lamination rates were found year-round. This is consistent with the occurrence and seasonal variation of the horizontal tracer gradient and vertical shear necessary for tilting the tracer surfaces. During winter, high lamination rates associated with the stratospheric polar vortex are present down to $\sim 100$ $\mathrm{hPa}$. Several features of the derived climatology are roughly consistent with earlier balloonborne studies. The patterns in the southern and northern hemisphere are comparable, but details differ as anticipated from a less disturbed and more symmetric southern polar vortex
\end{abstract}

\section{Introduction}

The instantaneous distribution of a trace constituent in the atmosphere depends not only on its chemical sources and sinks but also on its redistribution due to transport induced by various dynamical processes. Large-scale advection such as vortex erosion and wave-breaking [e.g., McIntyre and Palmer, 1984; Juckes and McIntyre, 1987; Hess and Holton, 1985; Hess, 1990; Bowman, 1993; Bowman and Mangus, 1993; Waugh et al., 1994] together with differential vertical shear [e.g., Murphy et al., 1989; Reid and Vaughan, 1991; Orsolini, 1995] provide the potential for folding and tilting of tracer surfaces that lead to filament-like tracer structures in the stratosphere. Concerns about ozone depletion within the polar vortex, and subsequent mixing of ozone depleted air into lower latitudes, have triggered much interest in these processes [World Meteorological Organization (WMO), 1986] since the induced horizontal and vertical scale reduction implies the mixing of air masses from substantially different origins, both in a dynamical and chemical context [e.g., Murphy et al., 1989; Pierce and Fairlie, 1993; Waugh et al., 1994; Plumb et al., 1994; Chen, 1994; Haynes and Anglade, 1997].

In a vertical sounding, tracer filaments can appear as layers of enhanced or depleted concentration referred to as laminated tracer structure. Ozone laminae of varying depth and magnitude have been observed since balloon soundings were available \footnotetext{
Bern, Switzerland.

Copyright 1997 by the American Geophysical Union

Paper number 97JD00066.

0148-0227/97/97JD-00066\$09.00
}

'Now at Climate and Environmental Physics, University of Bern [e.g., Dobson, 1973; Gardiner, 1988; Reid and Vaughan, 1991] and have also been found in lidar observations [Reid et al., 1993; Newman et al., 1996; Orsolini et al., 1997] and airborne in situ measurements [Murphy et al., 1989].

The distribution of laminae is highly variable both in space and time. Due to the lack of global stratospheric ozone measurements, only a limited number of climatological studies have been performed. Amplitudes of the local variations of the ozone mixing ratio typically show a peak in the mid stratosphere around $10 \mathrm{hPa}$ [U.S. Standard Atmosphere, 1976; also Andrews et al., 1987] and a seasonal variation with a maximum in midwinter and a minimum in midsummer [Roeth and Ehhalt, 1987]. A particular class of laminae characterized by an anomaly in ozone partial pressure [Dobson, 1973; Reid and Vaughan, 1991; Reid et al., 1993] has been observed to occur most commonly in winter and spring at high latitude and with a peak altitude of occurrence around 14 to $16 \mathrm{~km}$. In the summer season such strong ozone laminae were absent. The preferred occurrence near the winter polar vortex suggests that the likely cause of ozone laminae is differential advection of air masses of different origin which are interleaved in the vertical.

The above mentioned climatological studies are based on routinely performed balloon-borne ozone soundings using either a long time series for a single station or a pseudomeridional cross section based on 13 sounding stations in the northern hemisphere and 5 in the southern hemisphere [Reid and Vaughan, 1991]. The recently available satelliteborne ozone measurements provide a much higher global coverage; however, these data have not yet been widely used to address the issue of tracer lamination. Satellite data typically have poor vertical resolution compared to balloon soundings. Fortunately, recently developed contour advection techniques provide a powerful tool to dramatically increase the effective vertical and horizontal data resolution [e.g., Waugh and 

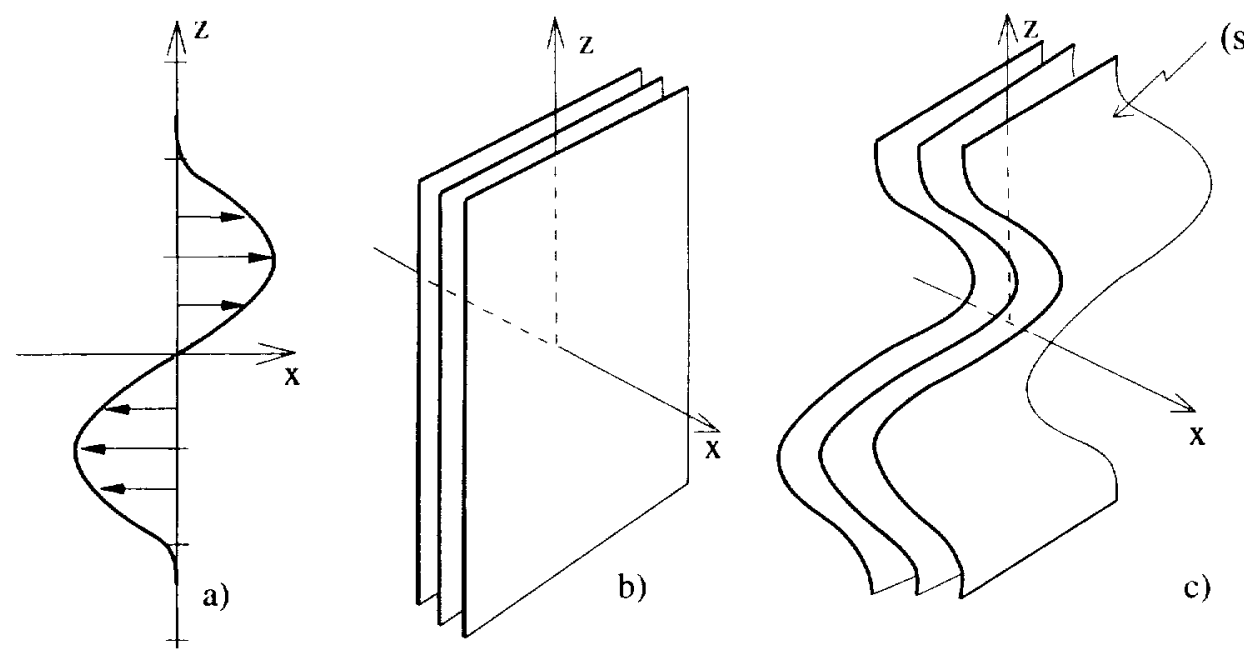

(s)
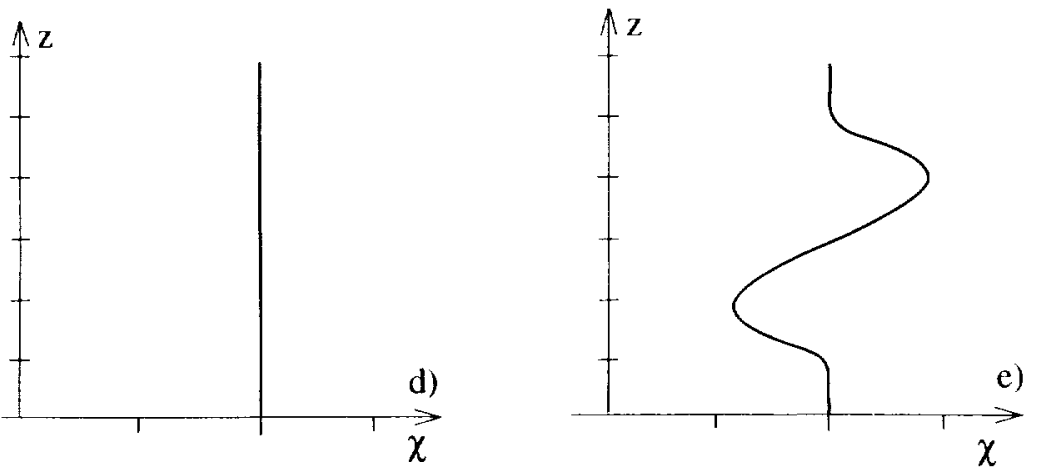

Figure 1. Schematic diagram illustrating the flow situation leading to high lamination rates.

Plumb, 1994; Waugh et al., 1994; Plumb et al., 1994; Chen et al., 1994; Pierce et al., 1994; also Appenzeller et al., 1996a]. Satellite ozone data have been used to trace back air masses in which laminae are embedded [Orsolini et al., 1995; Orsolini, 1995; Orsolini et al., 1997; Newman and Schoeberl, 1995; Newman et al., 1996] and have confirmed the involvement of air from the polar vortex. The successful contour advection simulations based on coarse wind analysis data suggest that comparatively large-scale flow features are responsible for the folding and tilting of tracer surfaces that finally lead to laminated structures.

A characteristic feature of any lamina or filament-like structure found in a vertical tracer sounding is a strong anomaly in the vertical tracer gradient of either positive or negative sign. The development of a laminated tracer structure can therefore be characterized by a temporal change of the vertical tracer gradient. This quantity will be referred to as the tracer lamination rate and will be explored in this study. Two types of tracer data will be used: coarse resolution satellite ozone measurements and a more highly resolved pseudotracer data set based on the atmosphere's potential vorticity (PV) structure. The results will be presented in the form of probability charts for the occurrence of high tracer lamination rates. This quantity can be interpreted as a proxy climatology of the production of laminated tracer (ozone) structures.

\section{Theory of Production of Vertical Tracer Gradients}

In Figure 1 the time development of a tracer lamina is schematically illustrated. The hypothetical tracer is assumed to have a horizontal distribution with a strong but localized tracer gradient near $x=0$ and two different constant tracer concentrations outside this region. For such a distribution the surfaces (s) with constant tracer mixing ratio $(\chi)$ are completely vertically oriented (Figure $1 \mathrm{~b}$ ) and a balloon sounding at any point in $x$ would show a constant tracer concentration (Figure 1d). Now assume that a vertical shear that is varying with height is acting on this tracer distribution (Figure la). After a certain time $t$ the tracer surfaces will be tilted away from their initial positions, thereby creating vertical tracer gradients of positive and negative signs (Figure $1 \mathrm{c}$ ). In a balloon sounding near $x=0$, the tilted tracer surfaces now appear as a tracer filament (Figure le). The strongest filament occurs in conjunction with the strongest horizontal tracer gradients. In essence, differential vertical shear that is not aligned with the tracer surfaces converts horizontal tracer gradients into vertical ones.

To quantify this mechanism, consider the conservation equation of a long-lived tracer with a volume mixing ratio $(\chi)$ : 


$$
\frac{D}{D t} \chi=S \cong 0
$$

Here a log pressure coordinate system as in Andrews et al. [1987] was used and

$$
\frac{D}{D t} \equiv \frac{\partial}{\partial t}+u \frac{\partial}{\partial x}+v \frac{\partial}{\partial y}+w \frac{\partial}{\partial z}
$$

represents the material derivative. $S$ is the net source term and is assumed to be zero. Taking the vertical derivative of equation (1), the material rate of change of the vertical tracer gradient can be expressed as

$$
\frac{D}{D t}\left(\frac{\partial \chi}{\partial z}\right)=-\frac{\partial u}{\partial z} \frac{\partial \chi}{\partial x}-\frac{\partial v}{\partial z} \frac{\partial \chi}{\partial y}-\frac{\partial w}{\partial z} \frac{\partial \chi}{\partial z}
$$

Using the geostrophic assumption the vertical shear is directly linked with the horizontal temperature gradient, i.e.,

$$
\left(\frac{\partial u}{\partial z}, \frac{\partial v}{\partial z}\right)=\left(-\frac{R}{H f} \frac{\partial T}{\partial y}, \frac{R}{H f} \frac{\partial T}{\partial x}\right)
$$

$H$ represents the scale height, $f$ the Coriolis parameter and $R$ the gas constant. Equation (2) can therefore be rewritten as

$$
\frac{D}{D t}\left(\frac{\partial \chi}{\partial z}\right)=-\frac{R}{H f}\left[\frac{\partial T}{\partial x} \frac{\partial \chi}{\partial y}-\frac{\partial T}{\partial y} \frac{\partial \chi}{\partial x}\right]-\frac{\partial w}{\partial z} \frac{\partial \chi}{\partial z}
$$

Since large-scale motions are quasi nondivergent, scaling suggests that the last term in equation (4) can be neglected compared to the term in the brackets and equation (4) simplifies to

$$
\frac{D}{D t}\left(\frac{\partial \chi}{\partial z}\right) \cong-\frac{R}{H f} \mathbf{k} \cdot[\nabla T \times \nabla \chi]
$$

The magnitude of the cross product of the horizontal gradients $(\nabla T, \nabla \chi)$ is therefore a measure of the production of vertical tracer gradients following the motion. The absolute value of this production rate will be referred to as the tracer lamination rate $(\mathfrak{f})$ :

$$
£ \equiv\left|\frac{D}{D t}\left(\frac{\partial \chi}{\partial z}\right)\right| \equiv \frac{R}{H f}|\mathbf{k} \cdot[\nabla T \times \nabla \chi]|
$$

The three-dimensional distribution of $£$ can be calculated from isobaric temperature and tracer distributions. This is particularly useful for satellite-measured tracer data since these data have a comparatively low vertical resolution. For the analyses shown below, equation (6) was evaluated using spherical coordinates.

In the winter stratosphere near the edge of the polar vortex, typical horizontal temperature gradients are $\nabla T \approx 20 \times 10^{-6}$ $\mathbf{K ~ ~ m ^ { - 1 }}$ and typical ozone gradients are $\nabla \chi \approx 1.5 \times 10^{-6} \mathrm{ppmv}$ $\mathrm{m}^{-1}$. For a hypothetical flow situation where the vertical shear is acting perpendicular to the tracer surfaces these values would result in lamination rates up to $f=10 \times 10^{-9} \mathrm{pp} \mathrm{mv}$ $\mathrm{m}^{-1} \mathrm{~s}^{-1}$ (with $R / H f=400 \mathrm{~J} \mathrm{~K}^{-1} \mathrm{~kg}^{-1} \mathrm{~m}^{-1} \mathrm{~s}$ ). Or equivalently, to produce a hypothetical lamina with a relative amplitude of $\sim 0.5$ ppmv and a vertical depth of $\sim 2 \mathrm{~km}$ about half a day would be needed.

\section{Data}

\subsection{MLS Ozone and Temperature Data}

The microwave limb sounder (MLS) from the Upper Atmosphere Research Satellite (UARS) provides stratospheric ozone and temperature measurements that can be used to construct daily global isobaric ozone charts (for more details about the MLS data see, e.g., the special issue dealing with UARS result in Geophysical Research Letters, 20, (12), 1993). In this study MLS Level $3 \mathrm{~b}$ data were used and the 13 Fourier components were gridded onto a coarse longitude latitude grid (with a lati-tudinal coverage between $80^{\circ} \mathrm{S}$ and $80^{\circ} \mathrm{N}$ and a horizontal resolution of $24^{\circ}$ longitude and $4^{\circ}$ latitude). In the vertical (i.e., between 100 and $1 \mathrm{hPa}$ ) the data have been interpolated onto UARS standard pressure levels. For the mid to upper stratosphere the data are of high accuracy [Froidevau: et al., 1996] but the data quality decreases for pressure greater than $-50 \mathrm{hPa}$. Therefore in the lowest stratosphere the ozone data should not be used for any physical interpretation. The 3 year averages shown below were constructed using all available data in the period from November 1991 to October 1994.

\subsection{Pseudotracer Potential Vorticity}

The second data set used is a pseudotracer based on the atmosphere's potential vorticity (PV) structure. Since on synoptic timescales both PV and ozone are roughly conserved quantities following an air parcel and both tracers have a comparatively

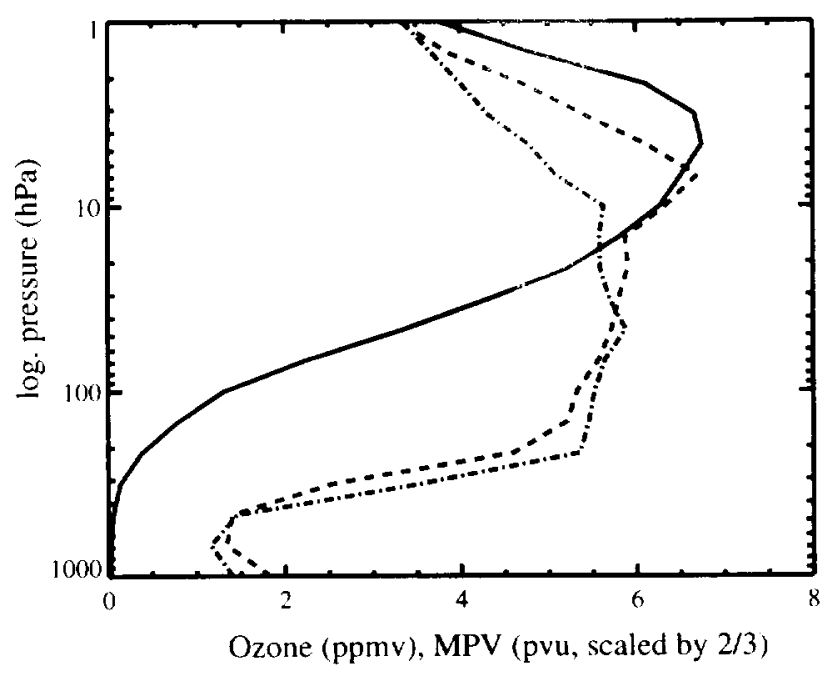

Figure 2. Vertical distribution of ozone (solid curve, given in parts per million by volume) and modified potential vorticity MPV (dashed curve, given in potential vorticity units scaled by $2 / 3$ ) for midlatitude winter based on U.S. standard atmosphere data. Dashed-dotted curve is MPV based on UKMO January climatology for 1993 at latitude $45^{\circ} \mathrm{N}$. 
strong meridional gradient, it can be anticipated that there exists a strong similarity in the pattern of their horizontal distribution. Strong horizontal gradients in both tracers can in particular be anticipated near the polar vortex edge and the tropopause. Unlike ozone, Ertel's PV as conventionally defined increases exponentially with height. Scaling of the Ertel PV as suggested by Lait [1994],

$$
M P V=P V\left(\theta / \theta_{0}\right)^{-9 / 2}
$$

allows for a vertical PV profile more comparable to that of ozone (Figure 2) without losing the fundamental conservation properties [Ertel, 1942]. The modified potential vorticity (MPV) was calculated from daily (00 GMT) global stratospheric analyses prepared by the United Kingdom Meteorological Office (UKMO) [Swinbank and O'Neill, 1994]. Horizontal winds, geopotential heights, and temperature data were used with a horizontal resolution of $2.5^{\circ}$ latitude by $3.75^{\circ}$ longitude. In the vertical, UARS standard pressure levels were used corresponding to a resolution of roughly $2.5 \mathrm{~km}$ ranging from $\sim 1000 \mathrm{hPa}$ to $1 \mathrm{hPa}$. The pseudotracer is displayed in standard PV units with 1 pvu $=10^{-6} \mathrm{~K} \mathrm{~m}^{2} \mathrm{~kg}^{-1} \mathrm{~s}^{-1}$. Pseudotracer lamination rates were not calculated at the two lowest pressure levels (i.e., 1000 and $681 \mathrm{hPa}$ ) as well as near the equator (i.e., between -10 and 10 latitude) and at the poles. It is important to keep in mind that these data represent a blend of sparsely available operational stratospheric observations with the model's own 6 hour forecast. Some of the small-scale PV features might therefore be artificially generated by the analysis procedure.

\section{Results}

\subsection{Maps}

Plate la shows an example of the northern hemisphere stratospheric polar vortex at $10 \mathrm{hPa}$ as seen by the MLS measurements. Ozone (black curves) and temperature (color) are shown. The temperature distribution was dominated by a wave number 2 pattern with cold temperatures over the Atlantic and warm ones over Siberia providing several regions with strong temperature gradients. The ozone pattern revealed that the polar vortex was shifted toward northern Europe and was characterized by relative low ozone concentrations compared to more southern latitudes. Relatively strong ozone gradients werc found at the edge of the polar vortex and also at midlatitudes stretched across the Atlantic to the Pacific. As anticipated, the overall horizontal pattern of the pseudotracer MPV truncated to the low MLS resolution (Plate 2a) closely resembled the observed ozone distribution (PJate la). Note the opposite sign in meridional gradient.

In Plates $1 \mathrm{~b}$ and $2 \mathrm{~b}$ the corresponding tracer lamination rates (equation (6)) are shown. Three regions with high lamination rates were found for both tracers, all of which are linked to the edge of the vortex: one over Europe, one over Siberia and a third over northern Canada. In these regions the ozone (pseudotracer MPV) gradients were relatively strong and not parallel to the temperature gradients as anticipated. Over the midlatitude Atlantic and the Pacific, the lamination rates were substantially lower despite relatively strong ozone (MPV) gradients.

The same calculations are shown in Plate 3 , but using the pseudotracer with full UKMO data resolution. The higher- resolution data set leads to a much finer-scaled and more localized tracer lamination field. Spots with high values occurred again in the three regions mentioned above and were in conjunction with strong pseudotracer gradients. Other small-scale features like the one over eastern Siberia $\left(160^{\circ} \mathrm{E}\right.$, $60^{\circ} \mathrm{N}$ ) lead also to enhanced production rates. These pseudotracer lamination rates were typically a factor $3 / 2$ higher than for the low-resolution data and a factor 10 higher compared to low-resolution ozone. A second illustrative example in the lower stratosphere $(\sim 100 \mathrm{hPa})$ is given in Plate 4. A tongue of high pseudotracer values extends southwestward from of the polar vortex stretching across Eurasia into a region with high temperature. Enhanced absolute values of tracer lamination rates occurred on both sides of the streamer, indicating that the vertical tracer gradients would increase on the southern and decrease on the northern side.

\subsection{Vertical Profiles}

Two vertical MLS ozone soundings taken within the region of high lamination rates over Europe (Plate $1 \mathrm{~b}$ ) are shown in Figure 3. The vertical profiles above $10 \mathrm{hPa}$ showed stronger vertical gradients compared to a 3 year monthly mean taken at the same grid points. This is consistent with the enhanced lamination rates shown above. Due to the poor horizontal and vertical resolution of the satellite data (i.e., roughly one measurement every $5 \mathrm{~km}$ in the vertical) the soundings can only resolve comparatively large-scale tracer structures and any smaller-scale laminac-like features are not resolved.

\subsection{Proxy Climatology}

In order to construct a global and seasonal climatology the tracer lamination rates were calculated for each day that tracer data were available (between November 1991 and October 1994). Subsequently the values were grouped into two main categories (see Table 1), group 1 containing no to weak lamination rates, group 2 moderate to strong lamination rates. A third group (group 3) was introduced to have some control over extremely high values. The combined group 2 and 3 will simply be referred to as high lamination rates. The results are given in the form of averaged probability charts (ranging from 0 to 1) to observe a particular group of lamination rates. Note that the longitude-latitude grid used is not equidistant in kilometers. The threshold values were chosen subjectively based on inspection of daily charts (compare with Plates 1 to 3 ) and were kept as simple as possible. Moderately changing the threshold value did not change the overall conclusion given below.

Meridional cross sections of monthly averaged charts of the probability to observe high (combined group 2 and 3) lamination rates are shown for low-resolution MLS ozone (Figure 4) in the altitude range 100 to $1 \mathrm{hPa}$ and for the high-resolution pseudotracer MPV (Figure 5) in the altitude range 1000 to $1 \mathrm{hPa}$. The data represent a 3 year average for the time periods January-February (Figures 4a and 5a) and July-August (Figures $4 b$ and $5 b$ ).

In the stratospheric overworld a clear difference between winter and summer season was found. In the winter season at midlatitudes and high latitudes high lamination rates occurred in both the MLS ozone ( -20 to $30 \%$ of all the cases) and in pseudotracer MPV ( $\sim 30$ to $40 \%$ of all the cases). In the summer season, even moderate production rates were absent. The pattern further suggests a slight asymmetry between the two 

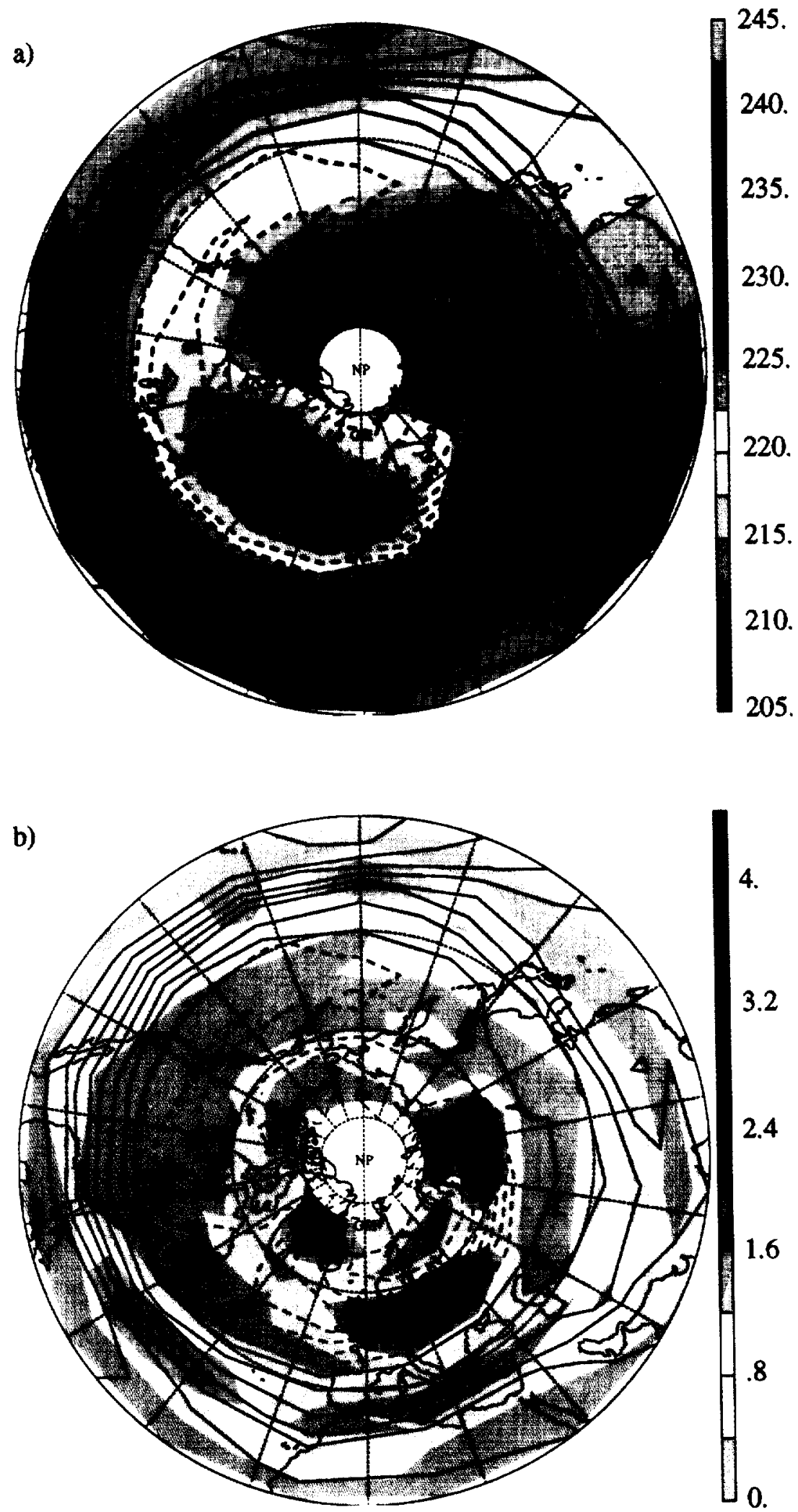

Plate 1. (a) Northern hemisphere ozone and temperature distribution as seen by MLS at $10 \mathrm{hPa}$ on March 18, 1992. Ozone volume mixing ratio is given by black curves (black dotted curves below 8 ppmv, interval $0.5 \mathrm{ppmv}$ ) and temperature is given in color (contour interval $2.5 \mathrm{~K}$ ). The area shown is northward of $20^{\circ}$. (b) Same as Plate $1 \mathrm{a}$, but calculated ozone lamination rates (colored, values given in units of $10^{-9} \mathrm{ppmv}$ $\mathrm{m}^{-1} \mathrm{~s}^{-1}$, contour interval $0.4 \times 10^{-9} \mathrm{ppmv} \mathrm{m}^{-1} \mathrm{~s}^{-1}$ ) and ozone volume mixing ratio overlaid (contours as in Plate 1a). 


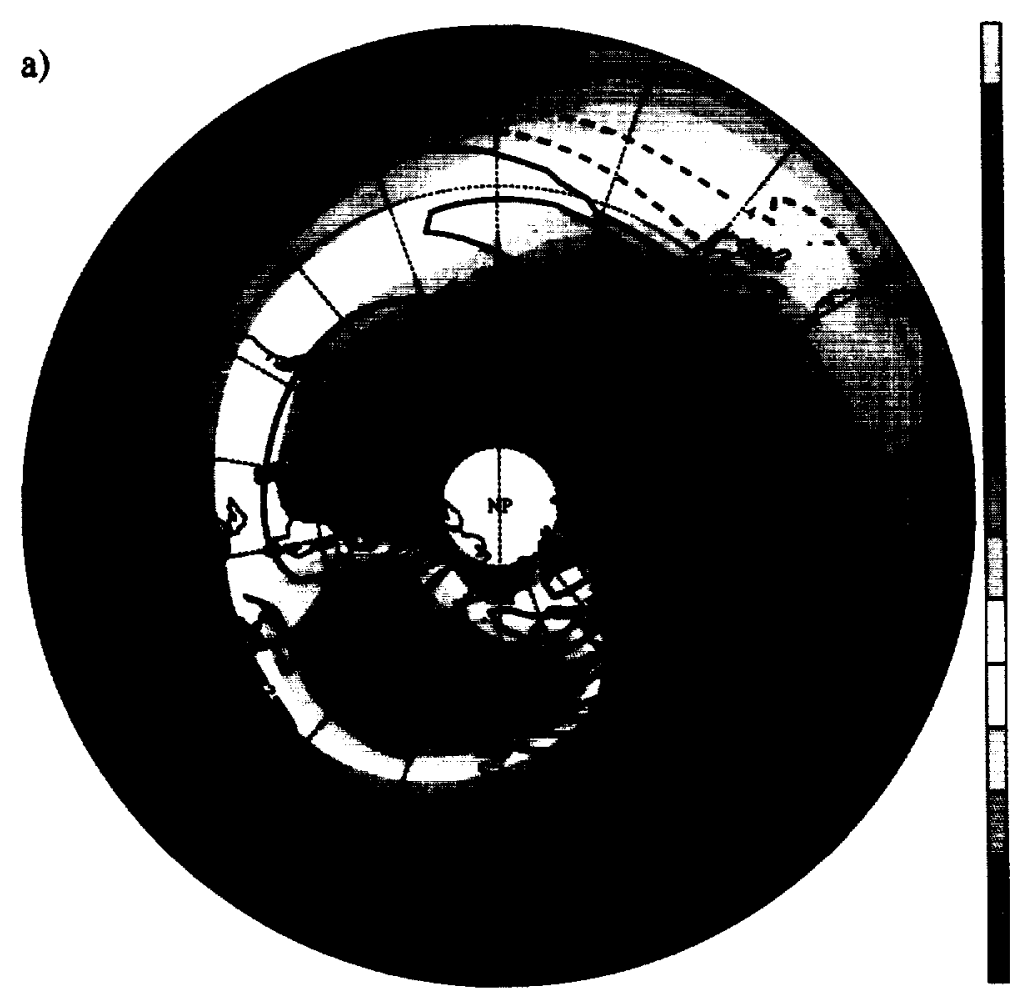

240.

235.

230.

225.

220.

215.

210.

b)

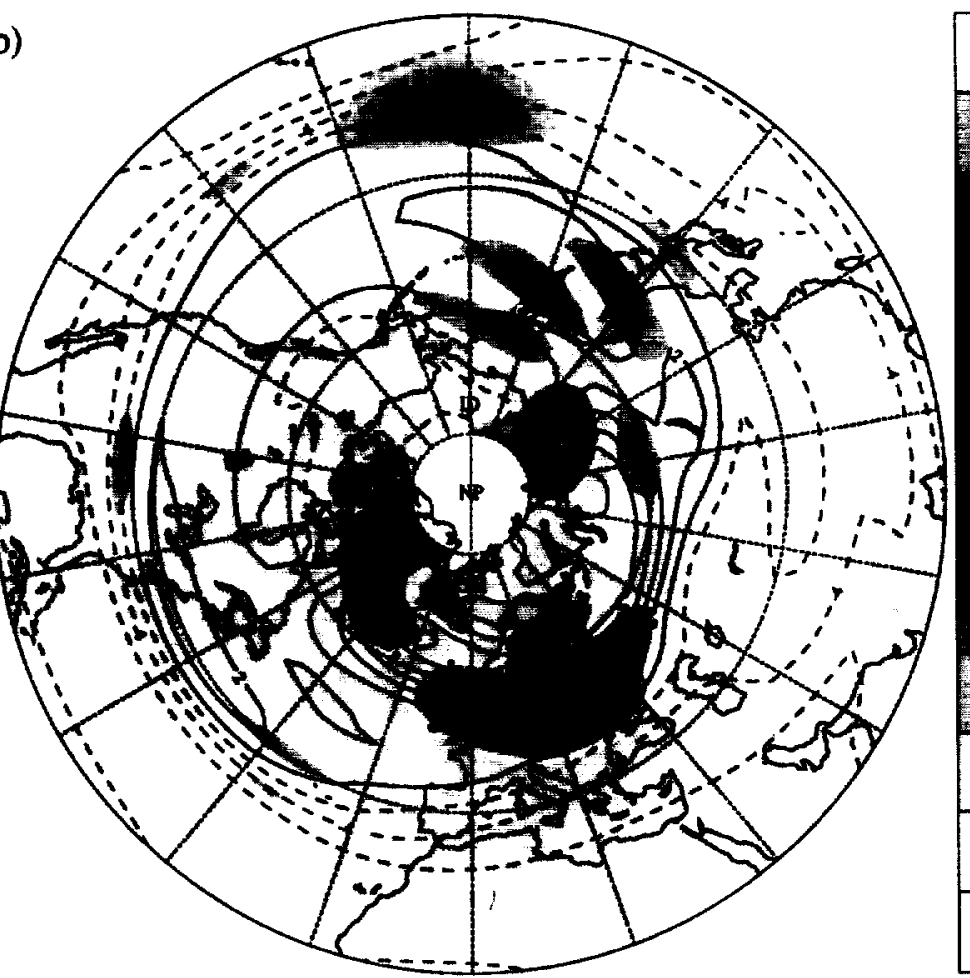

30.

25.

20.

15.

10.

5.

0.

Plate 2. (a) Same as Plate 1 but for pseudotracer MPV based on truncated UKMO potential vorticity structures. MPV is given by black curves (dotted curves below $10 \mathrm{pvu}$, interval $2 \mathrm{pvu}$ ) and temperature in color (contour interval $2.5 \mathrm{~K}$ ). (b) Same as Plate $2 \mathrm{a}$, but pseudotracer lamination rates based on truncated data

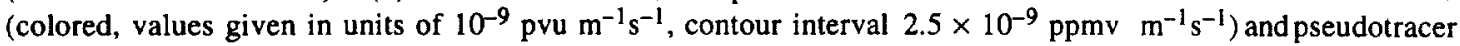
MPV overlaid (contours as in Plate 2a). 


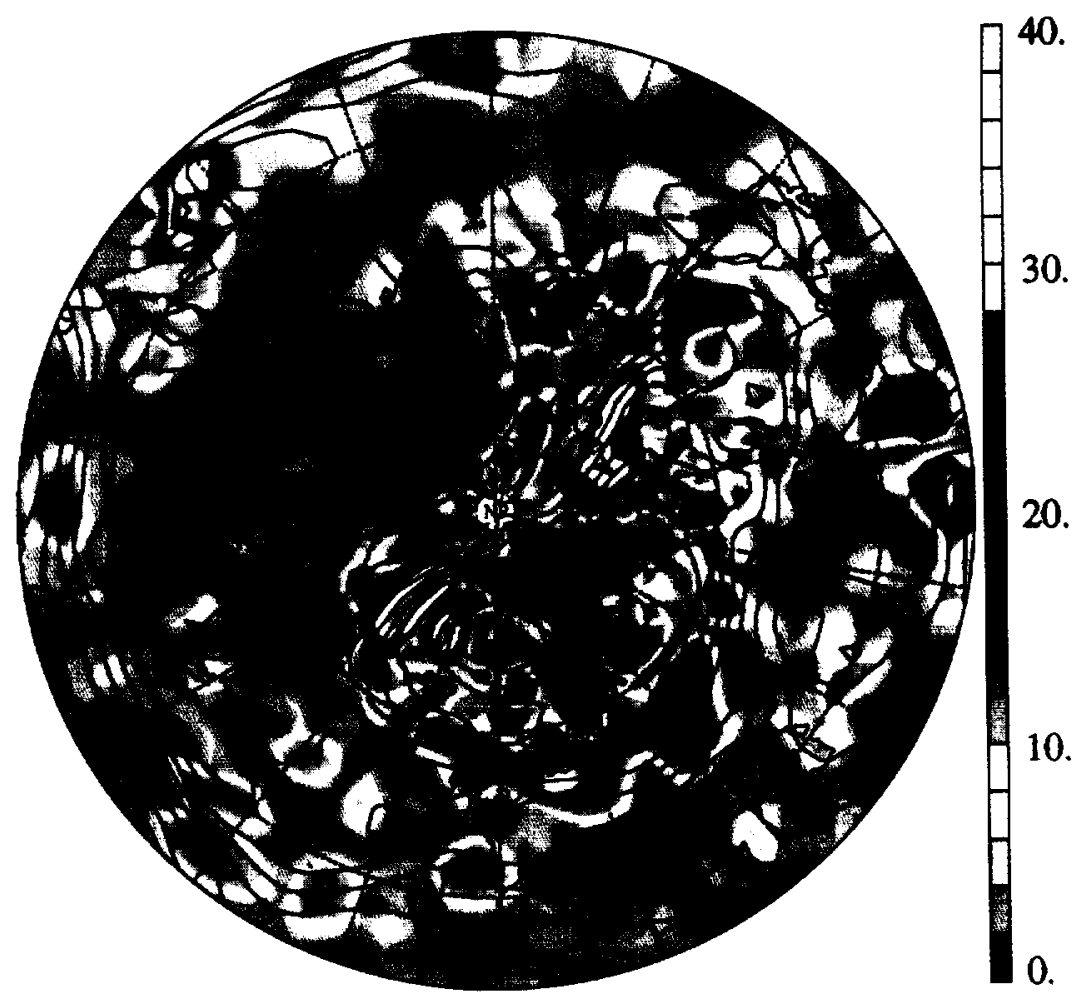

Plate 3. Same as Plate 2b, but pseudotracer MPV lamination rates based on full data resolution (colored,

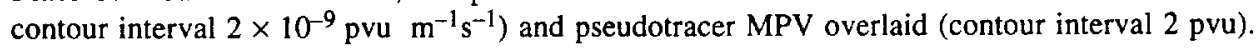

hemispheres. In the northern hemisphere the number of events increases with latitude, whereas in the southern hemisphere the region where high production rates occur seems to be more localized around a maximum at $-60^{\circ}$ south.

The analyses based on the pseudotracer (Figure 5) suggest two other regions in the atmosphere where high lamination rates occur, the lowermost stratosphere and the subtropical lower stratosphere (in both these regions no reliable MLS ozone data were available). In the midlatitudes, high values typically occurred between 400 and $200 \mathrm{hPa}$, whereas in the subtropical region the maximum is located between $\sim 120 \mathrm{hPa}$ and $60 \mathrm{hPa}$. In contrast to the variation in the stratospheric overworld the high lamination rates in the lowermost stratosphere were also present in the summer months.

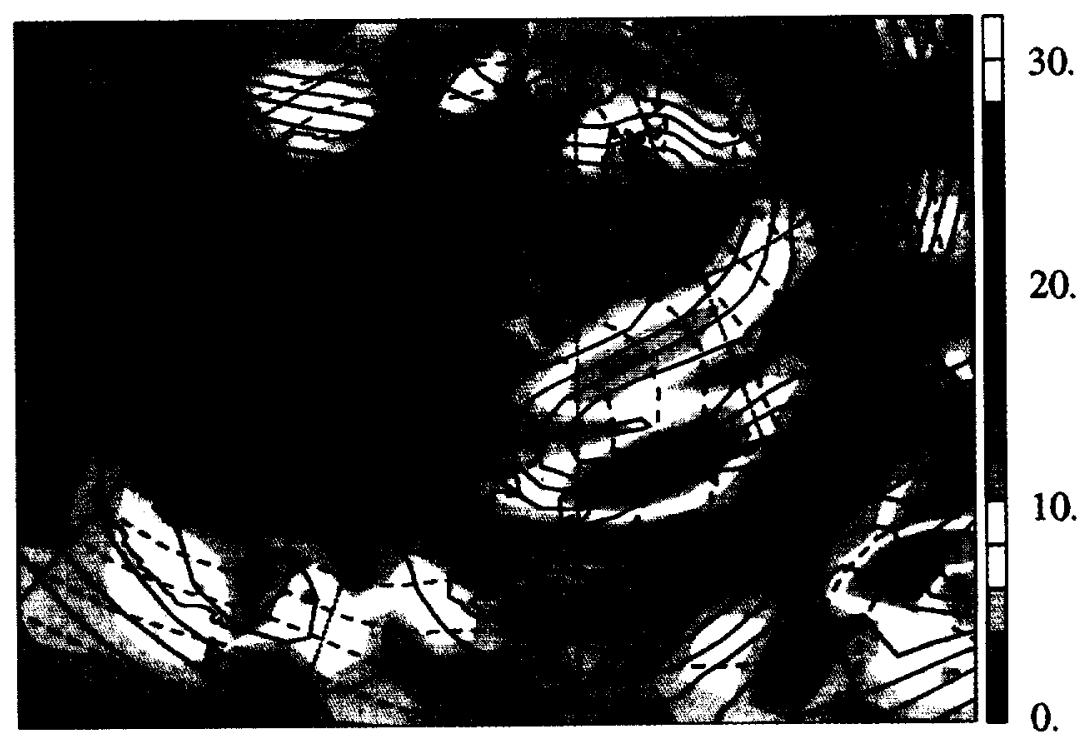

Plate 4. Lamination rates for pseudotracer MPV at $100 \mathrm{hPa}$ over Eurasia for January 1, 1993. Lamination rates are colored (contour interval $2 \times 10^{-9} \mathrm{pvu} \mathrm{m}^{-1} \mathrm{~s}^{-1}$ ), pseudotracer MPV overlaid in solid contours (contour interval $1 \mathrm{pvu}$ ), and temperature overlaid in dashed contours (contour interval $2.5 \mathrm{~K}$ ). 


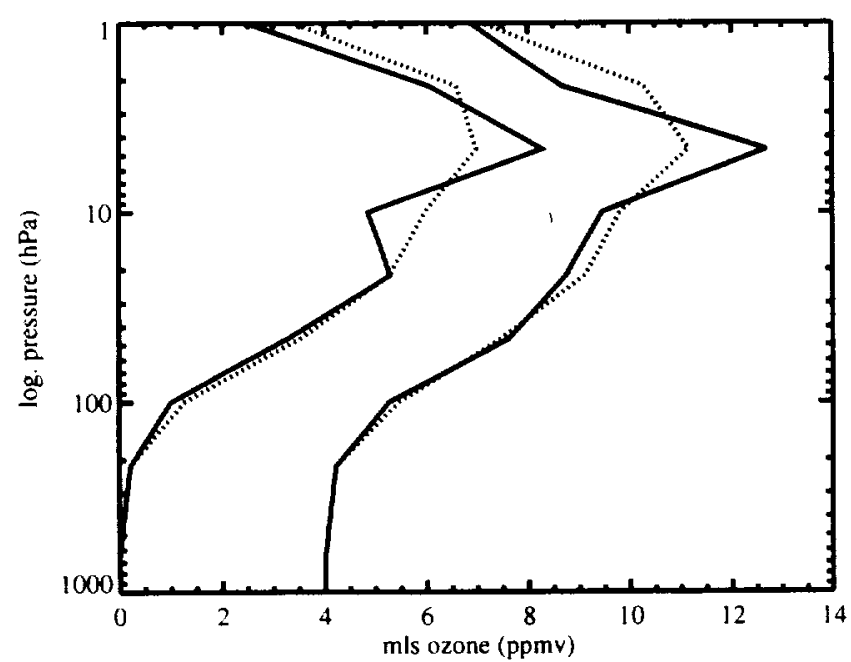

Figure 3. Vertical ozone distribution as seen by MLS at grid points $\left(12^{\circ} \mathrm{E}, 56^{\circ} \mathrm{N}\right)$ (left curves) and $\left(36^{\circ} \mathrm{E}, 56^{\circ} \mathrm{N}\right)$ (right curves) for March 18, 1992 (solid curves) and for a monthly mean (3 year average) at the same grid points (dashed curves). Locations are marked by stars in Plate $1 \mathrm{~b}$. Values given in parts per million by volume and curves shifted by 4 ppmv.

The complete seasonal variation of the probability of observing high lamination rates is shown in latitude time sections in Figure 6 (for MLS ozone) and Figure 7 (for the pseudotracer MPV). For better display the seasonal cycle is
Table 1. Threshold Values Used for Grouping the Tracer Lamination Rates (f)

Group Description No. $\mathfrak{E}$ MLS Ozone $£$ Pseudotracer MPV

\begin{tabular}{|c|c|c|c|c|}
\hline $\begin{array}{c}\text { Weak } \\
\text { lamination }\end{array}$ & no to weak & 1 & $\mathcal{E}<1 \times 10^{-9}$ & $\mathfrak{f}<10 \times 10^{-9}$ \\
\hline \multirow[t]{2}{*}{$\begin{array}{c}\text { Strong } \\
\text { lamination }\end{array}$} & $\begin{array}{l}\text { moderate to } \\
\text { strong }\end{array}$ & 2 & $\begin{array}{c}1 \times 10^{-9} \\
<£<3 \times 10^{-9}\end{array}$ & $\begin{array}{c}10 \times 10^{-9} \\
<\mathcal{E}<30 \times 10^{-9}\end{array}$ \\
\hline & $\begin{array}{l}\text { extremely } \\
\text { strong }\end{array}$ & 3 & $£>3 \times 10^{-9}$ & $£>30 \times 10^{-9}$ \\
\hline
\end{tabular}

Units of $\mathfrak{E}$ are parts per million by volume for ozone and potential vorticity units per meter per second for pseudotracer MPV.

shown twice. The data have been vertically averaged in three subregions of the stratosphere.

In the stratospheric overworld (Figures 6 and 7a), high lamination rates for both tracers occurred during the winter half-year and mainly poleward of $30^{\circ}$. For the southern hemisphere the time period was longer than for the northern hemisphere, consistent with the longer southern hemisphere winter. The period with high lamination rates was slightly longer in MLS ozone than for the pseudotracer data. In the northern hemisphere the highest probability was again found

a)

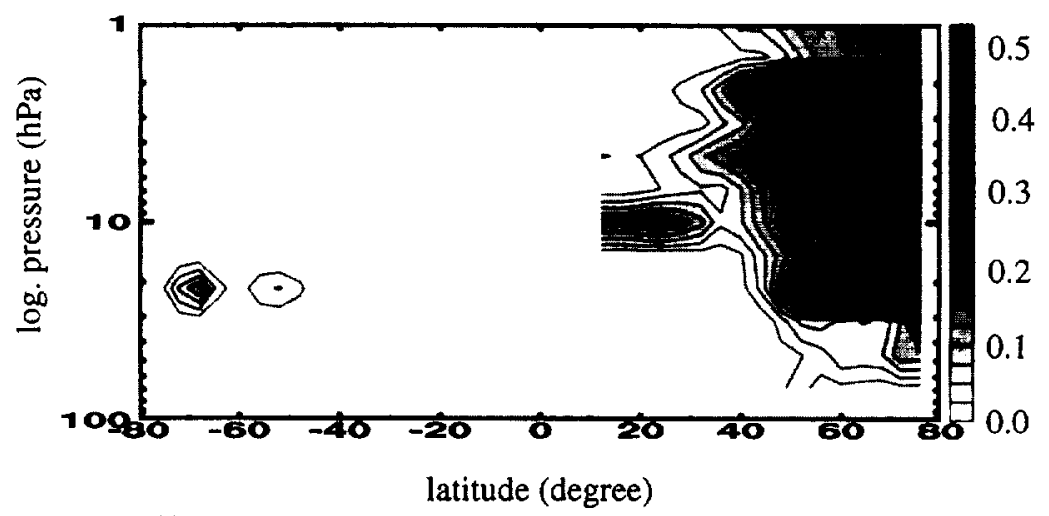

b)

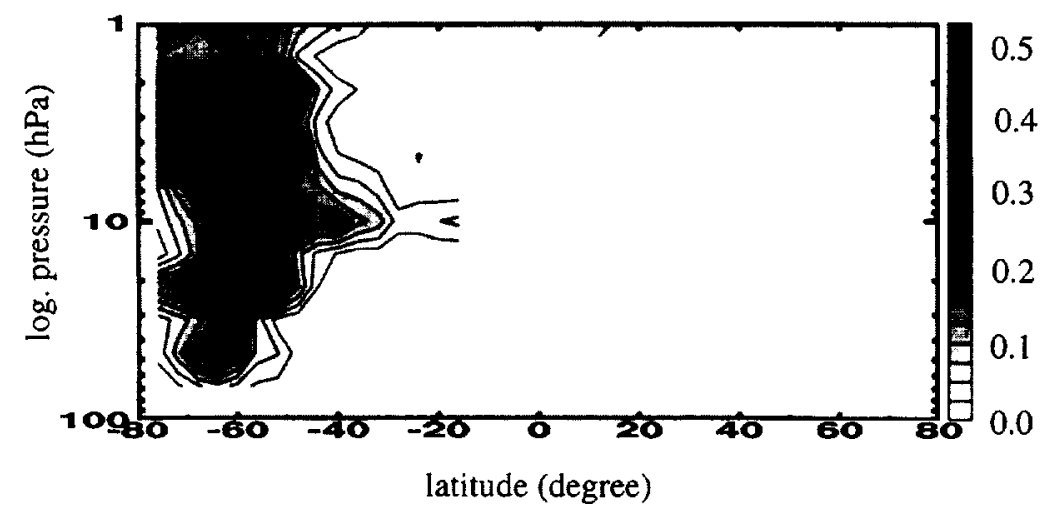

Figure 4. Latitude-height section of the probability of finding high ozone lamination rates for the period (a) January-February and (b) July-August. Data are based on MLS measurements and averaged over 3 years (1992 to 1994). Vertical axis ranges from 100 to $1 \mathrm{hPa}$. Data at $100 \mathrm{hPa}$ and near the equator $\left(+/-10^{\circ}\right.$ latitude) are omitted. Contour interval is 0.025 . 


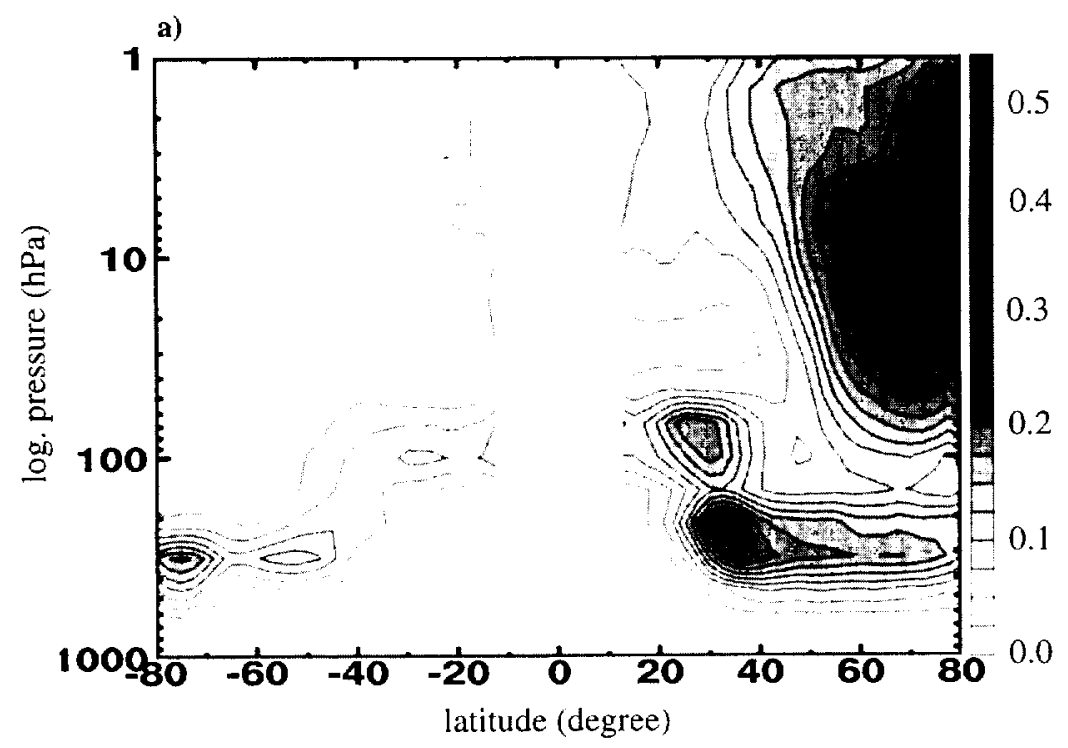

b)

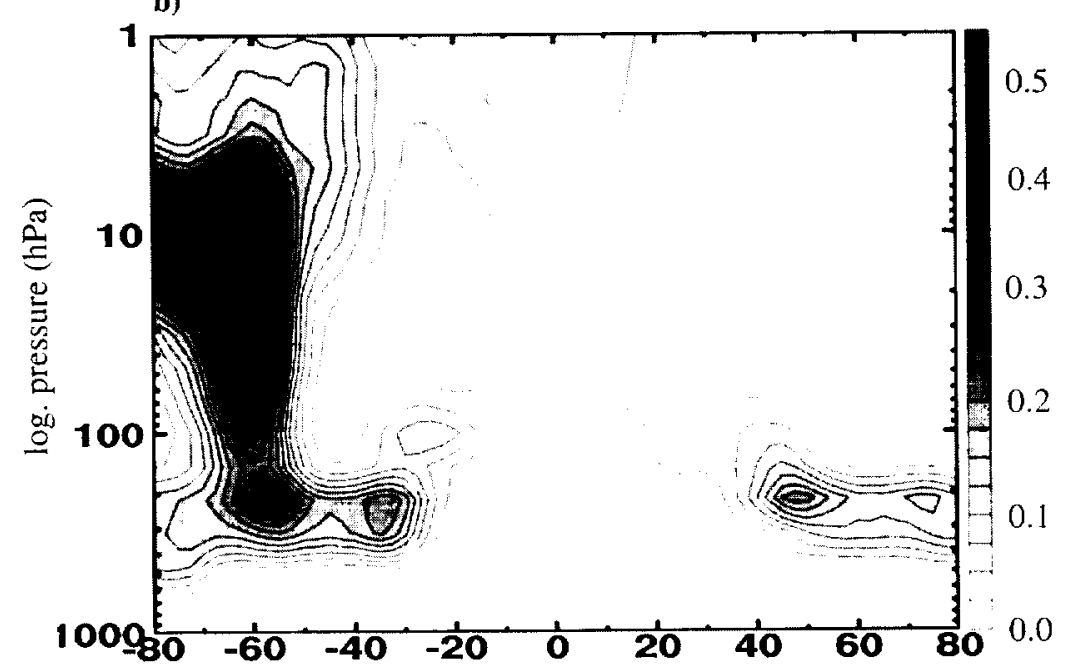

Figure 5. Same as Figure 4 but for the probability of finding high pseudotracer lamination. Data are based on UKMO analyses. Vertical axis ranges from 1000 to $1 \mathrm{hPa}$. Data below $650 \mathrm{hPa}$ and near equator are omitted. Contour interval is 0.025 .

at high latitudes, whereas in the southern hemisphere the maximum occurs again around $60^{\circ} \mathrm{S}$ (midwinter) and moved poleward during the spring season. Such a distribution is consistent with a less disturbed and more symmetric southern hemisphere polar vortex.

In the lowermost stratosphere (Figure 7b), high pscudotracer lamination rates were present throughout the year, but with substantially less probability and less horizontal extent during the summer season. The seasonal variation of the latitudinal coverage is consistent with the seasonal variation of the tropopause position [Appenzeller et al., 1996b]. In both hemispheres during the winter season a maximum occurred around $+/-30^{\circ}$ to $+/-40^{\circ}$ latitude near the subtropical tropopause break. It is interesting to note that Dobson [1973] suggested this to be the region where ozone poor air is entering the stratosphere.

Similar features can be observed at $100 \mathrm{hPa}$ (Figure 7c), but at higher latitudes the lamination rates showed a more pro- nounced seasonal cycle. In the northern hemisphere, high tracer lamination rates occurred only from January to mid-May and were completely absent from late spring to fall. A comparable seasonal cycle was found in earlier balloon studies [Reid and Vaughan, 1991] that examined the frequency of partial pres-sure laminae at the same altitude. These high lamination rates are associated with the lower edge of the stratospheric polar vortex. In the southern hemisphere the corresponding high probability region was observed below $100 \mathrm{hPa}$, i.e., clearly in the lowermost stratosphere (Figure 7b). At $100 \mathrm{hPa}$ the location of the maximum moved again poleward during the transition from winter to spring. In the northern hemisphere only a very weak indication of such a pattern could be found.

Finally, we note that extremely high lamination rates for both ozone and pseudotracer (characterized by the extra group 3 in Table 1) were only found in the stratospheric overworld (not shown separately). They occur in the 3 winter months pole- 


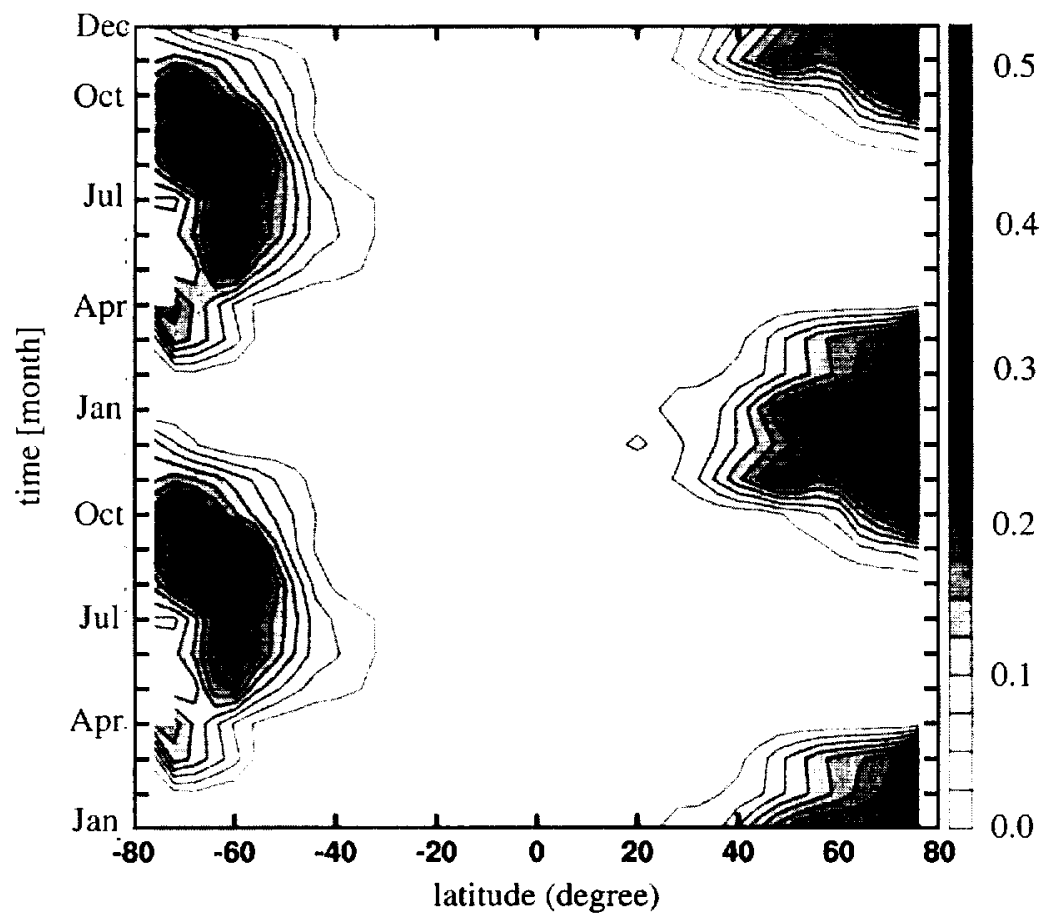

Figure 6. Seasonal variation of the probability of finding high ozone lamination rates in the stratospheric overworld. Data as in Figure 4, but a zonal and vertical (between 68 and $1 \mathrm{hPa}$ ) average. For display purposes the 3 year average is shown twice. Contour interval is 0.025 .

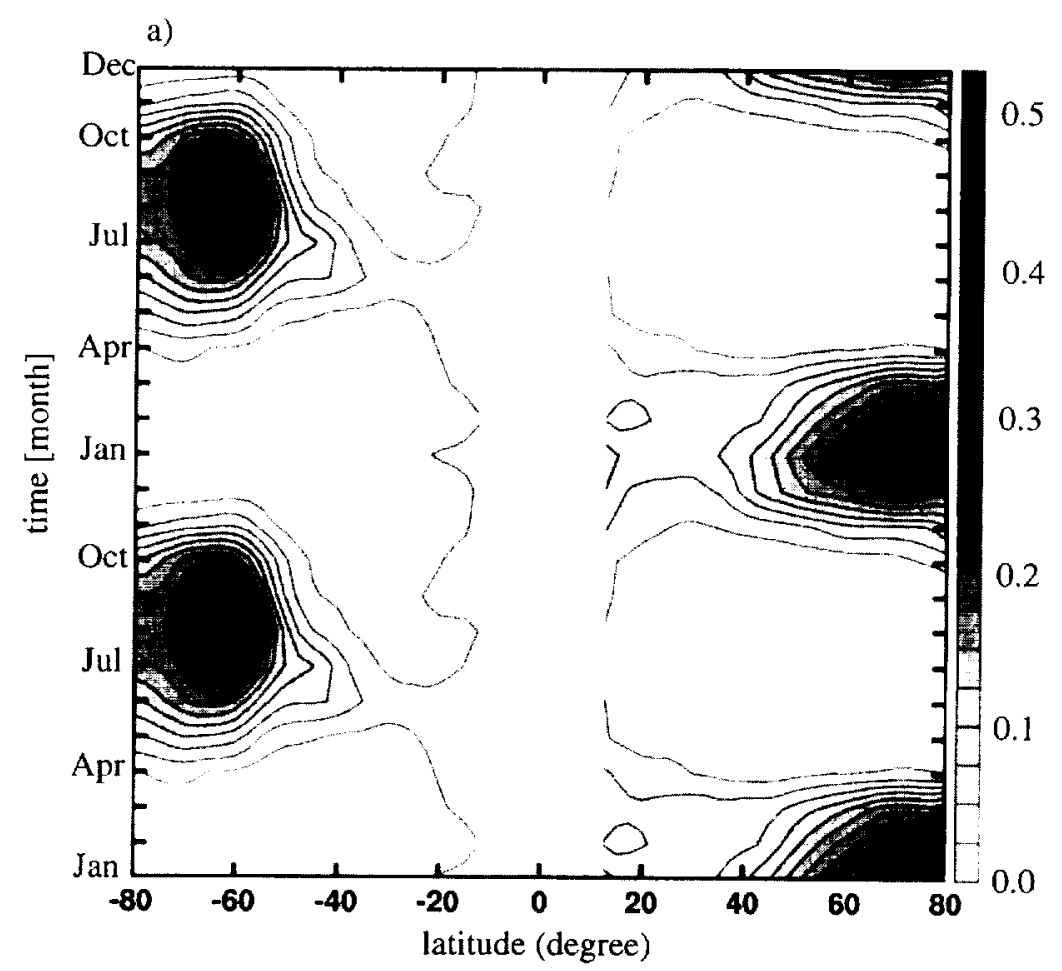

Figure 7. Same as Figure 6, but seasonal variation of the probability of observing high pseudotracer lamination rates. Data as in Figure 6. (a) Probability vertically averaged in the stratospheric overworld (between 68 and $1 \mathrm{hPa}$ ). (b) Probability vertically averaged in the lowermost stratosphere (between 316 and $146 \mathrm{hPa}$ ). (c) Probability at $100 \mathrm{hPa}$. Contour interval is 0.025 . 
b)

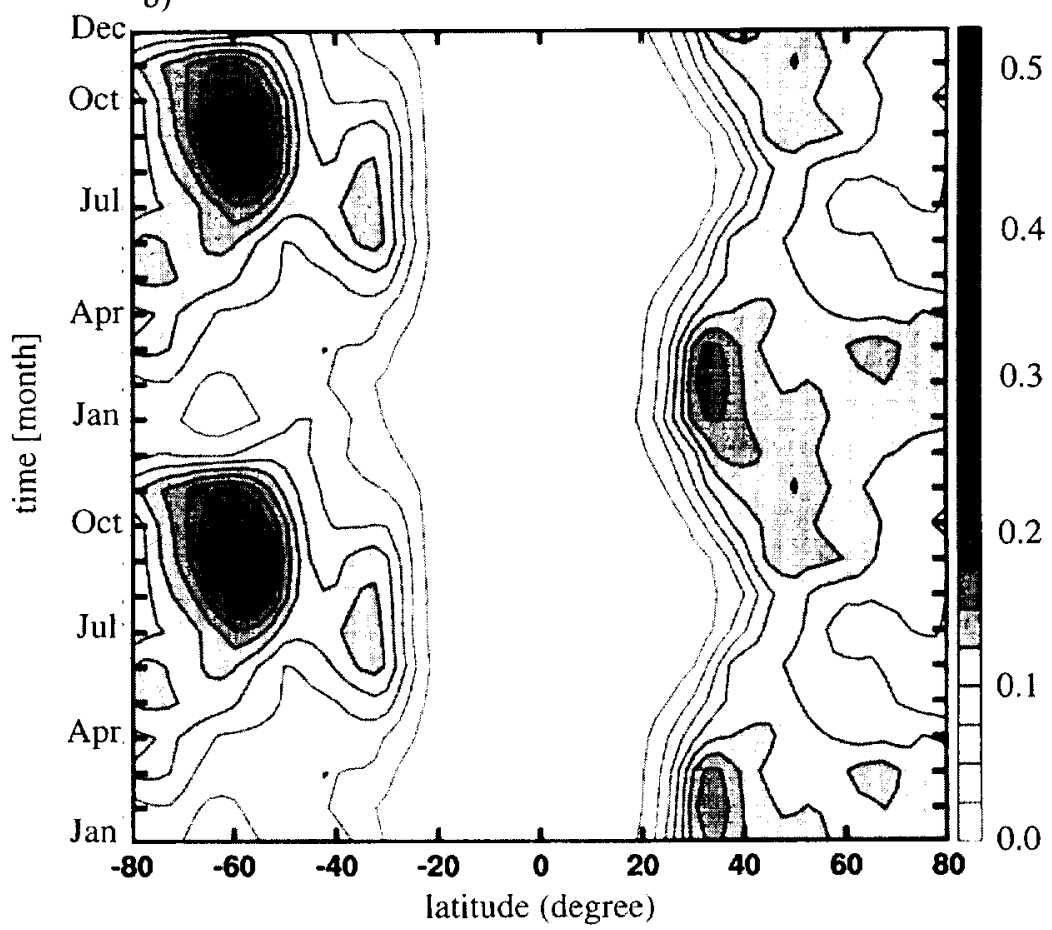

c)

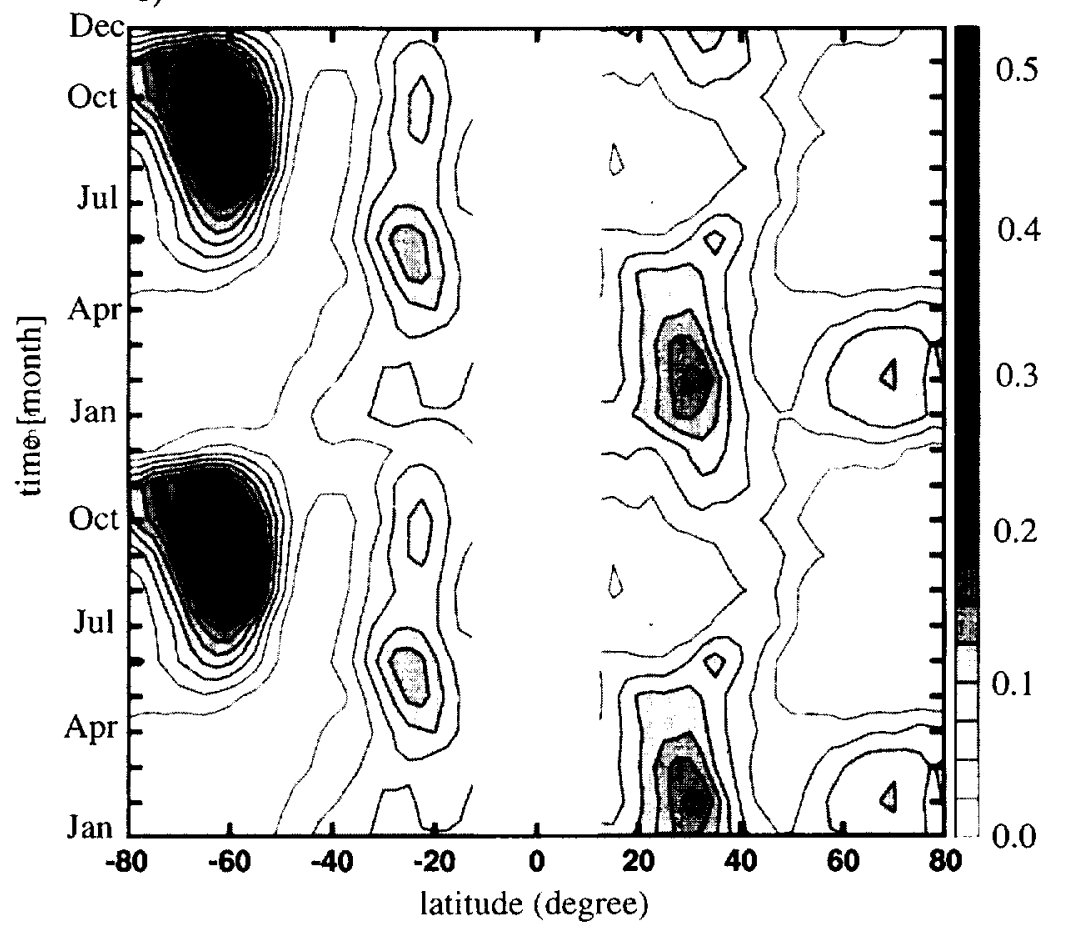

Figure 7. (continued)

ward of $\sim 60^{\circ} \mathrm{N}$ and in the southern hemisphere around $60^{\circ} \mathrm{S}$. The maximum probability of observing a class 3 lamination rate was $-10-15 \%$ in the northern and $-5-10 \%$ in the southern hemisphere. At $100 \mathrm{hPa}$ and in the lowermost stratosphere their contribution was negligible.

\section{Discussion}

Several features of the derived climatology are consistent with earlier studies based on balloon ozone soundings. These features include the preferred occurrence of filaments near the edge of the polar vortex [Reid and Vaughan, 1991; Reid et al., 1993, 1994], the preferred occurrence near the subtropical and midlatitude tropopause [Dobson, 1973], an increase in tracer variability in the mid stratosphere [Roeth and Ehhalt, 1987; U.S. Standard Atmosphere, 1976], a strong seasonal cycle with weak variability in the summer season [Dobson, 1973; Reid and Vaughan, 1991; Roeth and Ehhalt, 1987], and a shift of the maximum of occurrence toward the pole during the transition from winter to spring [Reid et al., 1993]. Other features found by the balloon studies, such as the absence of laminae in the mid to upper stratosphere and in the subtropical lower 


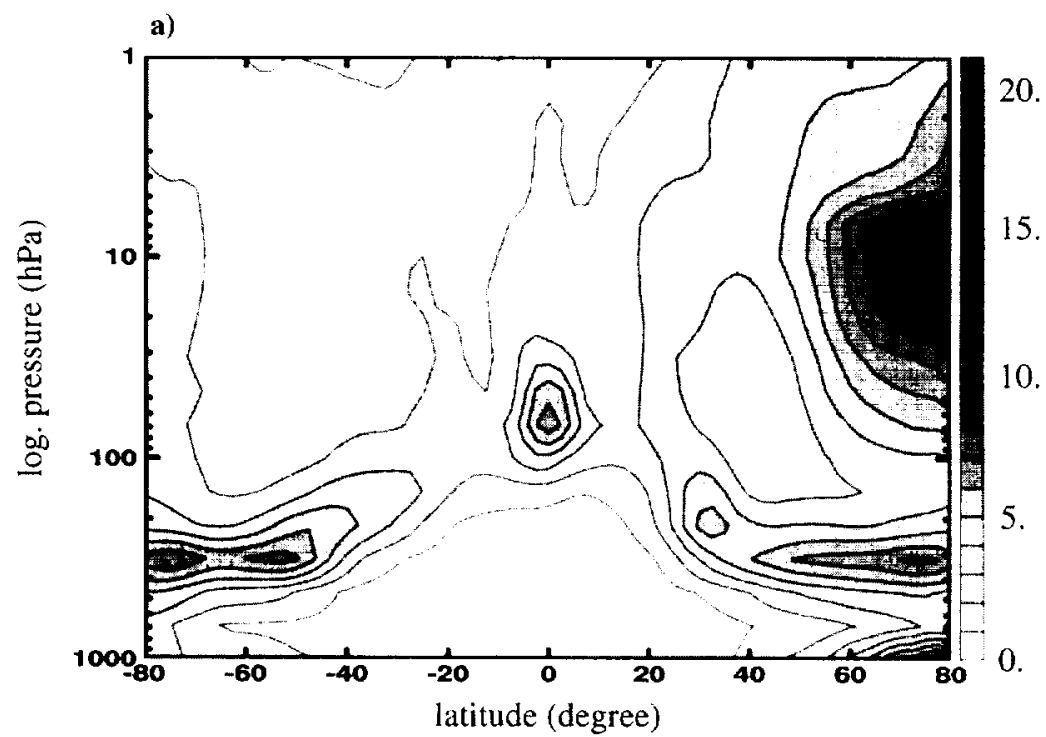

20.

15.

10.

b)

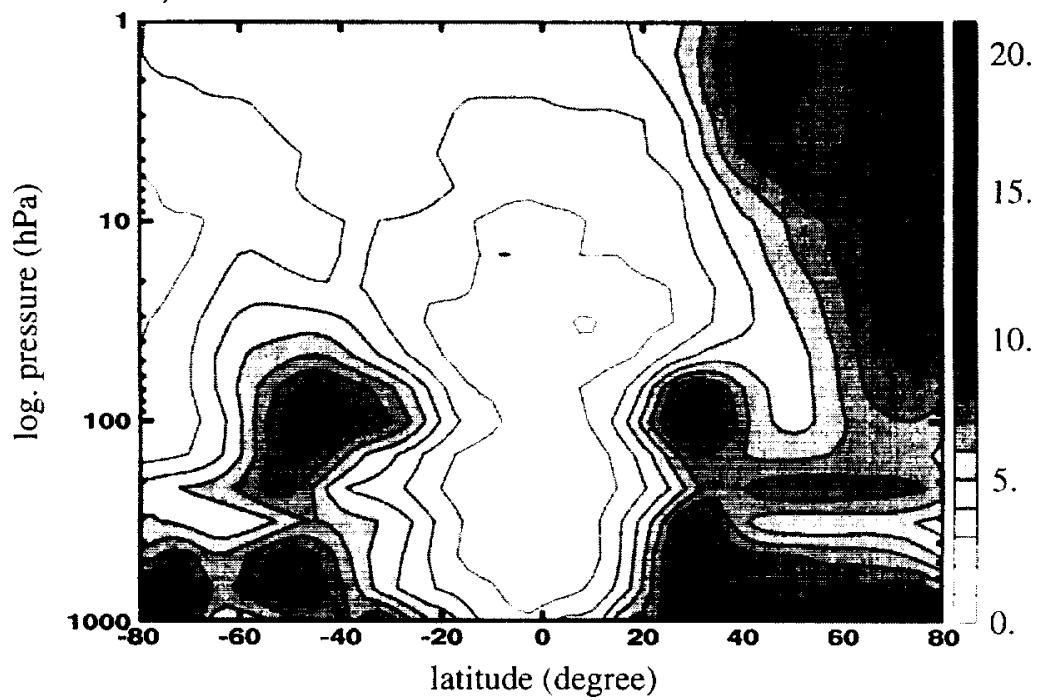

Figure 8. Zonally averaged magnitude of horizontal gradients in (a) pseudotracer MPV and (b) UKMO temperature. Data are averaged over 3 years (1992 to 1994) for the period January-February. Vertical axis ranges from 1000 to $1 \mathrm{hPa}$. (a) Values given in $10^{-6}$ pvu m $\mathrm{m}^{-1}$ and contour interval $1 \times 10^{-6} \mathrm{pvu} \mathrm{m}^{-1}$. (b) Values given in $10^{-6} \mathrm{~K} \mathrm{~m}^{-1}$ and contour interval $1 \times 10^{-6} \mathrm{~K} \mathrm{~m}^{-1}$.

stratosphere [Dobson, 1973; Reid and Vaughan, 1991], as well as the occurrence of laminae at high latitudes well into early June, are not found in the derived climatology. Part of this difference is due to the different laminae concept applied (see below).

Most of the distribution of high lamination rates can be understood in terms of the occurrence of both strong horizontal tracer gradients and the dynamical activity providing the vertical shear for tilting the tracer surfaces. Figure $8 \mathrm{a}$ shows a latitude-height section of the zonally averaged magnitude of horizontal pseudotracer gradients. As anticipated, regions with high averaged horizontal tracer gradients such as the tropopause region and the polar vortex region coincide roughly with regions characterized by high lamination rates (Figure 5). Regions with strong zonally averaged magnitude in vertical shear are shown in Figure $8 b$ (following equation (3), the shear is represented by the horizontal temperature gradient). High shear values also exist in regions with low lamination rates. An example is the subtropical lower stratosphere where strong vertical shears are present in both hemispheres but high pseudotracer lamination rates were only found in the northern (winter) hemisphere.

The summer middle stratosphere is not only characterized by weak pseudotracer gradients but also by weak vertic.ll shear. The latter is consistent with the seasonal variation in wave activity in the stratospheric overworld that is strongly determined by whether the stratospheric flow allows upward propagation of synoptic scale tropospheric wave sources. Linear wave theory [Charney and Drazin, 1961; Andrews et al., 1987 indicates that upward propagation of Rossby waves is inhibited in easterly winds. Figure 9 shows the seasonal variation of the probability of observing a west wind (i.e., allowing upward propagation) in the stratospheric overworld. Regions with probability higher than $80 \%$ are shaded. The 


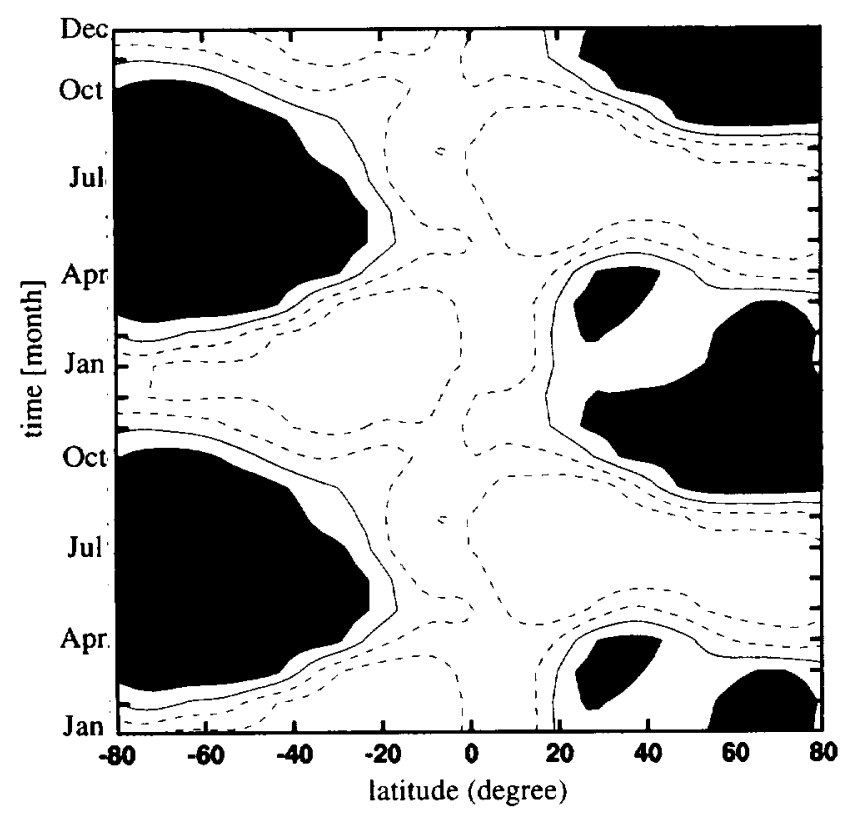

Figure 9. Seasonal variation of the probability of observing a west wind in the stratospheric overworld (averaged between 68 and $1 \mathrm{hPa}$ ). Regions with probabilities higher than 0.8 are solid shading, probability 0.6 is shown by solid lines, and probabilities less than 0.6 are dashed lines at 0.2 interval.

pattern reflects several features found in the seasonal variation of strong tracer lamination rates. Upward propagation is also limited to the winter half-year and occurs only poleward of approximately $30^{\circ}$ latitude. Again the winter period is longer in the southern hemisphere than in the northern, which is consistent with the less disturbed southern hemisphere's polar vortex.

These observations suggest that in the lower and lowermost stratosphere the occurrence of strong tracer lamination rates is mainly controlled by the existence of strong horizontal tracer gradients, since vertical shear is present throughout the year. In the mid to upper stratosphere, however, both the vertical shear and the strong horizontal gradients show a distinct seasonal cycle.

The climatological patterns of the occurrence of laminated ozone structures are dependent on how exactly a tracer or ozone lamina is defined. In the current study the occurrence of a high lamination rate that measures a strong increase or decrease of vertical gradient in tracer mixing ratio is used as a proxy for the occurrence of a laminated tracer structure. No limitation is applied on its vertical scale. The lamination rate itself is inferred from the tilting of the large-scale horizontal tracer gradient by the large-scale vertical shear. The balloon studies [Dobson, 1973; Reid and Vaughan, 1991; Reid et al., 1993] used a laminae definition based on a fixed ozone partial pressure $\left(p_{0}\right)$ anomaly of at least $2 \times 10^{-3} \mathrm{~Pa}$ and a vertical extent of less then $2.5 \mathrm{~km}$. Since ozone partial pressure decreases exponentially with height (i.e., $p_{0_{3}}=v_{0_{3}} p$ with $v_{0_{3}}$ the volume mixing ratio of ozone and $p$ the atmospheric pressure), a laminae climatology based on a fixed partial pressure anomaly substantially underestimates the variations found in the stratospheric overworld. The same is true for laminae frequency found in the subtropical lower stratosphere, since in this region the absolute ozone partial pressure values are comparable or smaller [Duetsch, 1978] than a typical threshold value used and therefore laminae defined on partial pressure anomalies ari: difficult to detect.

The observed climatology in the lower and lowermost stratosphere relies solely on the pseudotracer MPV. MLS ozone data could not be used to verify the existence of laminated ozone structures below the $50 \mathrm{hPa}$ surface. The pseudotracer has a somewhat better resolution than MLS ozone, but its distribution has only an approximate relation with that of ozone. For example, its maximum occurs at a lower altitude than the ozone maximum, and it decays faster in the upper stratosphere than does ozone (see Figure 2). However, according to equation (6) the tracer lamination rates are proportional to the absolute value of the horizontal tracer gradients and not to the value of the tracer concentration itself. For the tropopause region both tracers are characterized by comparatively strong gradients [e.g., WMO, 1986], whereas for the region in the subtropical lower stratosphere only a little information is available that supports the existence of strong horizontal ozone gradients [Duetsch, 1978; Fahey et al., 1996]. Finally, note that the occurrence of high lamination rates within the winter polar stratospheric vortex might be overestimated by small-scale structures artificially generated by the analysis scheme. Ozone data with better horizontal resolution covering the entire stratosphere would substantially improve the quality of this analysis.

\section{Conclusion}

Vertical soundings of stratospheric ozone often exhibit laminated tracer structures characterized by strong vertical gradients in mixing ratio. These laminae indicate the possible mixing of air masses of dynamically and chemically substantially different origin. Examples are the potential mass transport across the relatively isolated stratospheric polar vortex [e.g., Murphy et al., 1989; Waugh et al., 1994; Chen et al., 1994] or across the extratropical tropopause [e.g., Holton et al, 1995]. Both of these mixing processes substantially influence the atmosphere's ozone distribution and chemistry. Dynamically induced variations in stratospheric tracer concentration are also important for data assimilation purposes. Since most of the laminae are at or below the current model resolution, tracer assimilation in regions and seasons with high tracer lamination may prove to be an extremely difficult task.

The aim of this study was to provide a global and seasonal climatology of laminated ozone-like tracer structures in the stratosphere. Using the geostrophic assumption it was shown that production rates of vertical tracer gradients can be calculated by the cross product of the isobaric temperature and tracer gradients. This method permits calculation of tracer lamination rates based on satellite data with relatively low vertical resolution. The climatology presented was based on grouping lamination rates calculated from daily three-dimensional data sets rather then counting explicitly observed tracer laminae as in earlier studies. A high tracer lamination rate was taken as a proxy for the production of a laminated tracer structure. Two tracer data sets have been used, UARS satellite-borne lowresolution ozone measurements and higher-resolution ozonelike pseudotracer data based on modified potential vorticity. The ozone data were only available in the stratospheric overworld; the pseudotracer covered the entire stratosphere and was calculated from UKMO assimilated analyses. Comparisons of 
low-resolution charts of the corresponding lamination rates showed a qualitative good agreement. A similar calculation with more highly resolved pseudotracer data showed more localized regions with higher production rates. Comparison with single point ozone soundings would require a much higher-resolution data set.

The climatological analyses based on ozone and ozone-like pseudotracer data suggest that the stratosphere shows basically three regions with frequent occurrence of high ozone lamination rates. These are the part of the stratospheric overworld which is influenced by the polar vortex, the part of the lowermost stratosphere which is influenced by the tropopause and a third region in the subtropical lower stratosphere. Both the polar vortex and the tropopause are characterized by relatively strong horizontal ozone gradients. High lamination rates in the stratospheric overworld occur only during the winter half-year and are absent during summer, whereas high lamination rates in the lowermost stratosphere were found year-round. This is consistent with the occurrence and seasonal variation of the horizontal tracer gradient and vertical shear necessary for tilting the trace surfaces. The patterns in the southern and northern hemispheres are comparable, but details differ as anticipated from a less disturbed and more symmetric southern polar vortex. In the subtropical lower stratosphere a third region with high pseudotracer lamination rates was found. This region coincides mainly with strong vertical shear. Its relevance for ozone lamination is unclear. High lamination rates associated with the stratospheric polar vortex are present down to $\sim 100 \mathrm{hPa}$. In the northern hemisphere these high lamination rates occurred only from January to mid-May, which is roughly consistent with the seasonal cycle found in balloon-borne ozone partial pressure laminae.

Acknowledgments. This research was supported by the National Aeronautics and Space Administration (NASA), grants NAG 5-3188 (UARS) and NAG 1-1803.

\section{References}

Andrews, D. G., J. R. Holton, and C. B. Leovy, Middle Atmospheric Dynamics, San Diego, Calif., 1987, Academic, 489 pp.

Appenzeller, C., H. C. Davies, and W. A. Norton, Fragmentation of stratospheric intrusions., J. Geophys. Res., J0I, 1435-1456, 1996 a.

Appenzeller, C., J. R. Holton, and K. Rosenlof, Seasonal variation of mass transport across the tropopause, J. Geophys. Res., 101, 15,071-15,078, 1996b.

Bowman, K. P., Large-scale isentropic mixing properties of the Antarctic polar vortex from analyzed winds, J. Geophys. Res., 98, 23,013-23,027, 1993

Bowman, K. P., and N. J. Mangus, Observations of deformation and mixing of the total ozone field in the Antarctic polar vortex, J. Atmos. Sci., 50, 2915-2921, 1993.

Charney, J. P., and P. G. Drazin, Propagation of planetary-scale disturbances from the lower stratosphere into the upper atmosphere, J. Geophys. Res., 66, 83-109, 1961.

Chen, P., The permeability of the Antarctic vortex edge. J. Geophys. Res., 99, 20,563-20,571, 1994.

Chen, P., J. R. Holton, A. O'Neill, and R. Swinbank, Quasi-horizontal transport and mixing in the Antarctic stratosphere, J. Geophys. Res., 99, 16,851-16,866, 1994.

Dobson, G. M. B., The laminated structure of the ozone in the atmosphere, Q.J. R. Meteorol. Soc., 99, 599-607, 1973.

Duetsch, H. U., Vertical ozone distribution on a global scale, Pure Appl. Geophys., 116, 511-529, 1978.
Ertel, H., Ein neuer hydrodynamischer Wirbelsatz, Meteorol. Z., 59, 277-281, 1942.

Fahey, D. W., et al., In situ observation of $\mathrm{NO}_{\mathrm{y}}, \mathrm{O}_{3}$, and the $\mathrm{NO}_{y} / \mathrm{O}_{3}$ ratio in the lower stratosphere, Geophys. Res. Lett., 23, 1653-1656, 1996.

Froidevaux, L., et al., Validation of UARS MLS ozone measurements, J. Geophys. Res., 101, 10,017-10,060, 1996.

Gardiner, B. G., Comparative morphology of the vertical ozone profile in the Antarctic spring, Geophys. Res. Lett., 15, 901-904, 1988.

Haynes, P., and J. Anglade, The vertical-scale cascade of atmospheric tracers due to large-scale differential advection, J. Atmos. Sci., in press, 1997.

Hess, P., Variance in trace constituents following the final stratospheric warming. J. Geophys. Res., 95, 13,765-13,779, 1990.

Hess, P. G., and J. R. Holton, The origin of temporal variance in longlived trace constituents in the summer stratosphere, J. Atmos. Sci., 42 , 1455-1463, 1985.

Holton, J. R., P. H. Haynes, M. E. McIntyre, A. R. Douglass, R. B. Rood, and L. Pfister, Stratosphere-troposphere exchangc, Rev. Geophys., 33, 403-439, 1995.

Juckes, M. N., and M. E. McIntyre, A high-resolution one layer model of breaking planetary waves in the stratosphere, Nature, $328,590-$ 596, 1987.

Lait, L. R., An alternative form for potential vorticity, J. Atmos. Sci., 51, 1754-1759, 1994.

McIntyre, M. E., and T. N. Palmer, The "surf zone" in the stratosphere, J. Atmos. Terr. Phys, 46. 825-849, 1984.

Murphy, D. M., A. F. Tuck, K. K. Kelly, K. R. Chan, M. Loewenstein, J. R. Podolske, M. H. Profitt, and S. E. Strahan, Indictors of transport and vertical motions from correlations between in situ measurements in the Airborne Antarctic Ozone Experiment, J. Geophys. Res., 94, 11.669-11.685, 1989.

Newman, P. A., and M. Schoeberl, A reinterpretation of the data from the NASA stratosphere-troposphere exchange project., Geophys. Res. Lett., 22, 2501-2504, 1995.

Newman, P. A., et al., Measurements of polar vortex air in midlatitudes, J. Geophys. Res., 101, 12,879-12,891, 1996.

Orsolini, Y.J., On the formation of ozone laminae at the edge of the Arctic polar vortex, Q.J.R. Meteorol. Soc., 121, 1923-1941, 1995.

Orsolini, Y.J., P. Simon, and D. Cariolle, Filamentation and layering of an idealized tracer by observed winds in the lower stratosphere, Geophys. Res. Lett., 22, 839-842, 1995.

Orsolini, Y. J., G. Hansen, U. P. Hoppe. G. Manney, and K. Fricke, Dynamical modelling of wintertime lidar observations in the Arctic: Ozone laminae and ozone depletion, Q. J. R. Meteorol. Soc., in press, 1997.

Pierce, B. R., and T. D. A. Fairlie, Chaotic advection in the stratosphere: Implications for the dispersal of chemically perturbed air from the polar vortex, J. Geophys. Res., 98, 18,589-18.595, 1993.

Pierce, B. R. et al., Mixing processes within the polar night Jet, J. Atmos. Sci., 5I, 2957-2972, 1994.

Plumb, R. A. et al., Intrusion into the lower stratospheric Arctic vortex during the winter of 1991-1992, J. Geophys. Res., 99, 1089-1105, 1994.

Reid, S. J., and G. Vaughan, Lamination in ozone profiles in the lower stratosphere, Q.J.R. Meteorol. Soc., J17, 825-844, 1991

Reid, S. J., G. Vaughan, and E. Kyro, Occurrences of ozore laminae near the boundary of the stratospheric polar vortex, J. Geophys. Res., 98, 8883-8890, 1993.

Reid, S. J., G. Vaughan, N. J. Mitchell, I. T. Prichard, H. J. Smit, T. S. Jorgensen Varotsos, C., and $\mathrm{H}$. de Backer, Distribution of ozone laminae during EASOE and the possible influence of inertia-gravity waves, Geophys. Res. Lett., 2J, 1479-1482, 1994.

Roeth, E. P., and D. H. Ehhalt, Seasonal variation in the variance of stratospheric ozone and potential temperature over Hohenpeissenberg, F.R.G.: in Transport Processes in the Middle Atmosphere edited by G. Visconti and R. Garcia, pp. 137-152, D. Reidel, Norwell, Mass., 1987. 
Swinbank, R., and A. O'Neill, A stratosphere-troposphere data assimilation system, Mon. Weather Rev., 122, 686-702, 1994

U.S. Standard Atmosphere, U.S. Standard Atmosphere, 1976, U.S. Gov. Print. Off., Washington, D. C., 1976.

Waugh, D. W., and R. A. Plumb, Contour advection with surgery: A technique for investigating fine-scale structure in tracer transport, J. Atmos. Sci, 51, 530-540, 1994.

Waugh, D. W., et al., Transport out of the lower stratospheric Arctic vortex by Rossby wave breaking, J. Geophys. Res., 99, 1071-1088, 1994.
World Meteorological Organization, (WMO), Atmospheric Ozone 1985, Geneva, 1986

C. Appenzeller, Climate and Environmental Physics, University of Bern, Sidlerstrasse 5, CH-3012 Bern, Switzerland. (e-mail: christof@climate.unibe.ch)

J. R. Holton, Atmospheric Sciences, University of Washington, Seattle,WA 98195. (e-mail: holton@atmos.washington.edu

(Received August 16, 1996; revised October 23, 1996; accepted December 6, 1996.) 


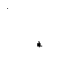

